\title{
Effect of coffee (caffeine) against human cataract blindness
}

\author{
This article was published in the following Dove Press journal: \\ Clinical Ophthalmology \\ 27 January 2016 \\ Number of times this article has been viewed
}

\begin{abstract}
Previous biochemical and morphological studies with animal experiments have demonstrated that caffeine given topically or orally to certain experimental animal models has significant inhibitory effect on cataract formation. The present studies were undertaken to examine if there is a correlation between coffee drinking and incidence of cataract blindness in human beings. That has been found to be the case. Incidence of cataract blindness was found to be significantly lower in groups consuming higher amounts of coffee in comparison to the groups with lower coffee intake. Mechanistically, the caffeine effect could be multifactorial, involving its antioxidant as well as its bioenergetic effects on the lens.
\end{abstract}

Keywords: caffeine, cataract, cataract blindness, cataractogenic process, intraocular pressure, vision impairment

\section{Introduction}

Cataract development is one of the major causes of visual impairment and eventual blindness. ${ }^{1,2}$ While cataract surgery has the potential of decreasing blindness due to this disease, the problem is so huge that it is difficult to eliminate it to the desired level, even by 2020. In fact, despite enhancement of surgical programs being undertaken in certain countries, the number of people with such vision impairment has been estimated to either remain stationary or even increase because of the simultaneous rise in population of the people over the age of 50. For example, in India, where there is a highly serious effort to increase the number of surgery, the number of people with cataractrelated visual impairment and blindness is projected to increase from 7.75 million noted in 2001 to 8.25 million in 2020 because of the increase in the population in general, as well in the population of people over 50 years of age. ${ }^{3}$ Additionally, its overall incidence is expected to remain relatively stationary because of the replacement of people with cataracts by the newer people and increasing the global incidence of diabetes including that in the developing countries. This is expected to have additional impact on the incidence of cataracts as well as some retinal diseases. As determined by the World Health Organization (WHO), the overprevalence of blindness due to cataract has remained steady to approximately 50\% through 2010 . Additionally, it is recognized that country-wise differences in cataract-related blindness is also related to certain other confounders such as genetics, environmental, and various nutritional factors known to be involved in maintaining the lens in a transparent state. For example, the cataractogenic process starts at a much younger age in Southeast Asia than in the Western countries. The prevalence of cataract is also related to the intensity and duration of solar radiation at particular places. This is largely demonstrated by the higher incidence of cataracts in the tropics.
Correspondence: Shambhu D Varma Department of Ophthalmology and Visual Sciences, Biochemistry and Molecular Biology, University of Maryland School of Medicine, 10 South Pine Street, Baltimore, MD 21042, USA

Tel +l 4107063395

Email svarma@som.umaryland.edu 
We have previously shown that an intraocular penetration of visible and ultraviolet (UV) radiation initiates photochemical formation of certain highly reactive species of oxygen in the aqueous humor and lens. These species are commonly referred to as reactive oxygen species (ROS). The common species are superoxide, hydrogen peroxide, hydroxyl radical, and singlet oxygen that play a central role in inflicting oxidative stress to the tissue and its opacification. ${ }^{4-6}$ Thus, the formation of cataract is expected to be highly modulated by the presence of antioxidant nutrients in the diet and their passage through the blood aqueous barrier, such as ascorbate and vitamin E, known to act as potent scavengers of the ROS. Thus, the local nutritional culture, adopted or native, can have a significant modulating role. An immediate effect of ROS generation is to deplete the lens of its antioxidant reserves such as glutathione, which in turn can lead to oxidative modifications of its membrane lipids and proteins. We have recently shown that this depletion of antioxidants can also be followed soon by an overall genetic dysregulation, induced by an upregulation of the generation of microRNAs (miRNAs) and consequent gene silencing. ${ }^{7,8}$ Initial evidence to the involvement of oxidative stress in the etiology of cataract formation was provided by a number of organ culture studies showing biochemical and structural damage to the tissue induced by various ROS. Addition of ROS scavengers including vitamin C, $\alpha$-tocopherol, bioflavonoids, chlorogenic acid, and pyruvate to the culture medium has been found to be highly protective. ${ }^{9-14}$ The role of oxidative stress in the pathogenesis of cataract has been demonstrated in vivo by the preventive effect of ROS scavengers against cataract formation in intact experimental animal models, ${ }^{15-19}$ as well as by a number of human studies with antioxidant vitamins. ${ }^{20-23}$ More recently, we have shown that caffeine, a common constituent of many food products, can also protect the lens against oxidative stress in vitro as well as in vivo. ${ }^{24-28}$ The in vivo effectiveness has been demonstrated by its preventive effect against cataract formation in rats fed a diet rich in galactose, a highly active cataractogenic sugar that simulate the formation of diabetic cataracts. It is effective if given systemically mixed with the diet, ${ }^{29}$ as well as when administered topically by application of caffeine drops. ${ }^{27,28}$ Additionally, it also inhibits UV-induced cataract in vitro as well in vivo. In the former case, it was shown by its protective effect against damage to the lens organ culture in the absence as well as in the presence of kynurenine..$^{24,25}$ In the latter case, its topical application has been found to be effective against cataract formation induced by exposing rabbits to UV-B. ${ }^{30}$ That its actions are attributable to its ability to act as scavenger of ROS was further proven by electron spin resonance studies. ${ }^{31-33}$ While acting as a
ROS scavenger, it also represses the transcription of toxic miRNAs. ${ }^{34}$ Based on these studies showing anticataractogenic effect of the compound in experimental animals, it was considered desirable to investigate if its use as a dietary constituent could be involved as a factor in modulating the formation of cataracts in humans also.

\section{Methods}

This possibility has been investigated by correlating the prevalence of cataract blindness in different countries with the amount of caffeine consumed there in, per person. Data on the prevalence of cataract blindness were obtained from the population-based studies, where the blindness due to cataract was determined along with the contribution of various other eye diseases such as glaucoma, age-related macular degeneration, corneal opacities, diabetic retinopathy, childhood blindness, trachoma, onchocerciasis, and others, consolidated by WHO in $2004 .{ }^{2}$ Cataract has been found to account for approximately $50 \%$ of the total blindness, a figure found to be little affected at least until 2010 and expected to remain so at least till 2020.

Since coffee is the primary source of caffeine, its intake was determined from its per capita coffee consumption (kg/year). This information was obtained from the Food and Agriculture Organization of the United Nations (http://www.griequity.com/resources/BusinessGuides/ DemographicsData/energy/energy-resourceconsn.pdf Table ERC.5), ${ }^{35}$ as well as from the alphabetical listings and maps available online with www.ChartsBin.com. They all describe consumption of Coffea arabica, the primary variety of the coffee used throughout the world. ${ }^{33,34}$ Additional data were obtained from www.wiseGEEK.com. ${ }^{38}$ The amount of caffeine derived from the coffee consumed was calculated from its percentage composition in the arabica beans, which is close to $1 \%(10 \mathrm{mg} / \mathrm{g})$. The beans for beverage preparation are normally roasted at $220^{\circ} \mathrm{C}$ for improving its taste and aroma. Since its melting point is rather high $\left(238^{\circ} \mathrm{C}\right)$, its loss during the roasting process is small..$^{39,40}$ On the other hand, other possible physiologically active agents present in the beans such as the chlorogenic acids,${ }^{41}$ are destroyed by isomerization, hydrolysis, and pyrolysis during roasting. The small traces likely to be left over during roasting are destroyed further by heating of the roast with steaming hot water during beverage preparation by the continuous drip method or by heating with microwave irradiation. The physiological activity of the coffee is thus largely attributable to its caffeine content, acting by virtue of its effectiveness as a scavenger of hydroxyl radical or other modes such as the inhibition of phosphodiesterase or as an adenosine antagonist. 
The amount of caffeine present in the beverage prepared from tea (Camellia sinensis), despite a higher concentration of caffeine per gram of the tea leaves, is known to be much lower than the coffee prepared from arabica. This is due to the relatively much smaller quantity of the tea leaves used in the beverage preparation. This is consistent also with the much higher incidence of cataracts in most tea-consuming countries instead of coffee, such as India, Pakistan, Bangladesh, Myanmar, People's Republic of China, and other Southeast regions, as compared with the coffee-consuming countries with some exceptions where tea is used in excessive amounts, such as Turkey where the use of tea is maximum in the world, deriving $376 \mathrm{mg}$ of caffeine per day. The caffeine they derive from the coffee is only approximately $10 \mathrm{mg} / \mathrm{day}$, and yet they have lower incidence of cataract attributable to the high amounts they derive from tea.

\section{Results}

Table 1 summarizes the global data on the incidence of cataract blindness in different countries, expressed as a percentage of total blindness by WHO,, 12 along with the consumption of coffee in terms of caffeine intake per day,

Table I Cataract prevalence and caffeine consumption

\begin{tabular}{|c|c|c|c|}
\hline Zone & Country name & $\begin{array}{l}\text { Cataract incidence } \\
\text { (\% of total blindness) }\end{array}$ & $\begin{array}{l}\text { Caffeine consumption } \\
\text { (mg/day) }\end{array}$ \\
\hline \multirow[t]{6}{*}{ Zone I } & Benin & 64 & 0 \\
\hline & Ghana & 62.5 & 0 \\
\hline & Nigeria & 50 & 0 \\
\hline & Congo & 55 & 0 \\
\hline & Mali & 50 & 0 \\
\hline & Togo & 50 & 0 \\
\hline \multirow[t]{11}{*}{ Zone 2} & Kenya & 55 & 2.70 \\
\hline & Sierra Leone & 50 & 2.74 \\
\hline & Mauritania & 50 & 2.74 \\
\hline & Tanzania & 55 & 2.80 \\
\hline & Paraguay & 40 & 5.47 \\
\hline & Niger & 50 & 4.76 \\
\hline & Cameroon & 50 & 5.47 \\
\hline & Guinea & 50 & 8.22 \\
\hline & Vanuatu & 65 & 8.20 \\
\hline & Central African Republic & 55 & 8.20 \\
\hline & Tunisia & 48.5 & 10.13 \\
\hline \multirow[t]{7}{*}{ Zone 3} & South Africa & 55 & 11.00 \\
\hline & Morocco & 49 & 24.65 \\
\hline & Oman & 48.5 & 27.39 \\
\hline & Saudi Arabia & 48.5 & 43.8 \\
\hline & Barbados & 40 & 27.39 \\
\hline & Brazil & 40 & 26.00 \\
\hline & Bulgaria & 28.5 & 79.0 \\
\hline \multirow[t]{7}{*}{ Zone 4} & Turkey & 28.5 & 10.95 \\
\hline & Turkmenistan & 35.5 & 54 \\
\hline & Belarus & 24 & 16 \\
\hline & Hungary & 24 & 84.93 \\
\hline & Latvia & 24 & 93.15 \\
\hline & Lithuania & 24 & 112 \\
\hline & Ukraine & 24 & 38.5 \\
\hline \multirow[t]{12}{*}{ Zone 5} & USA & 7.6 & 226 \\
\hline & Canada & 5 & 178 \\
\hline & Denmark & 5 & 271 \\
\hline & Finland & 5 & 328 \\
\hline & France & 5 & 148 \\
\hline & Iceland & 5 & 246 \\
\hline & Ireland & 5 & 104 \\
\hline & Italy & 5 & 162 \\
\hline & the Netherlands & 5 & 230 \\
\hline & UK & 5 & 200 \\
\hline & Norway & 5 & 271 \\
\hline & Australia & 5 & 202 \\
\hline
\end{tabular}

Note: The zones labeled I-5 represent countries in areas specified with the following WHO abbreviated names: Afr D, Afr E, Emr B and D, Eur C, and Eur A, respectively. Abbreviation: WHO, World Health Organization. 
per person. The grouping of the countries used in the table is identical to that done by WHO. However, for convenience, the group name has been replaced by numbered zones. The numbered geographic zones represent the countries as indicated in Table 1. Information on caffeine consumption ( $\mathrm{mg} /$ day/person) in the individual countries of the groups was derived from the country-wise listing of per capita coffee consumption in sources as mentioned earlier.

A first glance of the table clearly suggests that the incidence of cataract blindness in the countries varies noticeably with the variation in caffeine intake. It indicates a relatively higher incidence of cataracts in countries with lower intake of coffee, also showing vice versa that the incidence of cataract blindness is lower in countries with its higher intake, with expected data scatter. However, a decreasing correlation between the increase in caffeine intake and lowering of cataract incidence was more convincingly demonstrated if the caffeine intake and the cataract prevalence data were analyzed interzonally, and group-wise, as summarized in Table 2.

As can be seen by reference to groups in Table 2 , the percentage of cataract blindness in zone 1 is as high as $64 \%$, which corresponds to coffee consumption of near zero. The mean cataract blindness in this group was $55 \% \pm 6 \%$. That a consumption of coffee by this group and consequent availability of caffeine in their diet could have attenuated this high incidence of cataract was inferable from the reference to the cataract incidence summarized in zone 2 . The cataract blindness incidence in this group decreased perceptibly from the mean of $55 \%$ in zone 1 to $52 \%$, with an increase in caffeine intake from 0 to $5.6 \pm 2.72 \mathrm{mg} /$ day. Although this decrease in cataract was not statistically significant, it was adequate to suggest that a further increase in caffeine intake could lead to a more significant and visible decrease of cataract development. That indeed has been found to be the case. As noticeable in zone 3 , increase in caffeine use to $34.2 \mathrm{mg}$ /day was now associated with the further decrease in cataract generation to $44.21 \%$. Increasing the caffeine consumption to $48 \mathrm{mg} / \mathrm{day}$,

Table 2 Zone-wise data showing decreasing incidence of cataract with increase in caffeine intake

\begin{tabular}{llll}
\hline Zone & Caffeine intake (mg/day) & Cataract incidence (\%) & $\mathbf{n}$ \\
\hline 1 & 0 & $55.25 \pm 6.56(2.66)$ & 6 \\
2 & $5.6 \pm 2.720(0.860)$ & $51.68 \pm 6.51(1.93)$ & 10 \\
3 & $34.28 \pm 21.94(8.95)$ & $44.21 \pm 8.74(3.56)$ & 6 \\
4 & $48.02 \pm 46.28(18.88)$ & $26.28 \pm 4.39(1.79)$ & 6 \\
5 & $213.83 \pm 61.58(19.48)$ & $5.21 \pm 0.75(0.23)$ & 13 \\
\hline
\end{tabular}

Note: The values are expressed as mean \pm standard deviations and standard errors of the means.

Abbreviation: $\mathrm{n}$, the number of countries in each zone. the cataract blindness decreased to $26.2 \% \pm 3 \%$. Increase of caffeine consumption to $198 \mathrm{mg}$ /day, the cataract blindness was now highly minimized, the cataract incidence being now only approximately $7.6 \%$, in the USA. The effect of caffeine was significant also in the eastern European regions such as Latvia, Lithuania, Hungary, Ukraine, Belarus, Turkey, and Turkmenistan. Other areas of the world including India, People's Republic of China, and other South Asian countries where caffeine consumption is $<2.0-5 \mathrm{mg} /$ day, cataract is also known to be very high, the contribution of cataract to blindness reaching up to $70 \% .^{3}$ The lower consumption of coffee in Turkey and Turkmenistan with a relatively lower incidence of cataract blindness was initially intriguing. But this is explainable by the finding that Turkish (culturally) have the highest tea consumption in the world, $6.87 \mathrm{~kg} /$ year (18.8 g/day) with a caffeine content of $20 \mathrm{mg} / \mathrm{g}$. The daily consumption comes out to be $376 \mathrm{mg} /$ day. Turkmenistan uses $0.82 \mathrm{~kg} /$ day, given caffeine intake data of $45 \mathrm{mg}$. This obviously has an additive factor with its coffee consumption. The results therefore show a significant relationship between the higher caffeine intake and lower incidence of cataract blindness. Statistical analysis of the data in Table 2 is shown in Table 3. It is clear that the significance of findings (the $t$ values determined by Student's $t$-test and $P$-values determined from standard $t$ table) increases from lower to the higher level of caffeine consumption, the final $P$ level reaching to 0.0001 .

The inhibitory effect of caffeine in humans is also indicated by the graphical representation of the total data in Table 1 and the trend line as shown in Figure 1. A negative correlation between the caffeine intake and the incidence

Table 3 Intergroup $t$ and $(P)$ values for caffeine intake and cataract blindness

\begin{tabular}{|c|c|c|}
\hline Interzone & Caffeine intake & Cataract blindness \\
\hline Between 2 and I & $5.02(0.005)$ & $1.16(0.23)$ \\
\hline Between 3 and I & $3.81(0.0034)$ & $2.48(0.03)$ \\
\hline Between 4 and I & $2.54(0.0293)$ & $9.04(0.0001)$ \\
\hline Between 5 and I & $8.35(0.0001)$ & $16.77(0.000 \mathrm{I})$ \\
\hline Between 3 and 2 & $4.16(0.001)$ & $2.12(0.0626)$ \\
\hline Between 4 and 2 & $2.96(0.0103)$ & $8.87(0.000 I)$ \\
\hline Between 5 and 2 & I0.62 (0.00I) & $27.77(0.00 I)$ \\
\hline Between 4 and 3 & $0.662(0.5527)$ & $6.05(0.001)$ \\
\hline Between 5 and 3 & $6.75(0.000 \mathrm{I})$ & $16.52(0.00 \mathrm{I})$ \\
\hline Between 5 and 4 & $5.84(0.001)$ & I7.33 (0.000I) \\
\hline
\end{tabular}

Clinical Ophthalmology 2016:10 


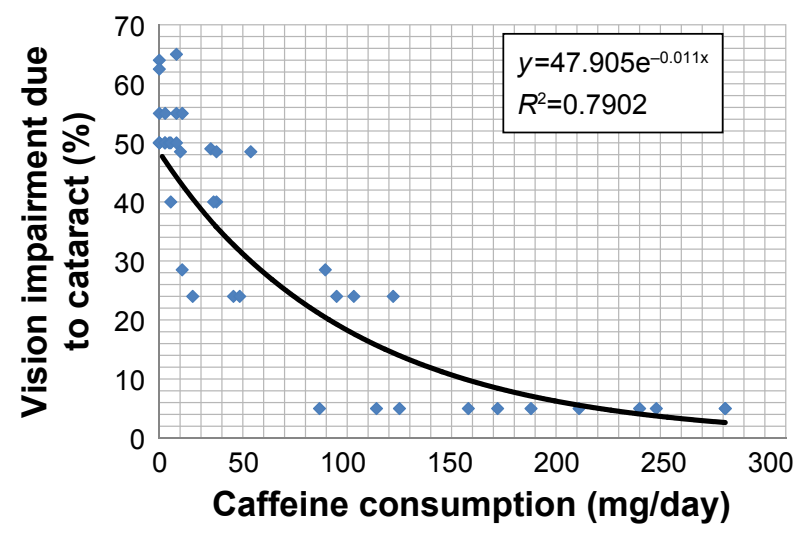

Figure I Regression analysis.

Notes: The graph shows an inverse correlation between vision impairment (\%) due to cataract and caffeine intake ( $\mathrm{mg} /$ day). As may be noted, the downward correlation between caffeine intake and the cataract incidence is highly apparent with coefficient of correlation and inhibition of cataract blindness with caffeine is highly significant, with $R^{2}$ value approaching 8 . The Spearman's rank-order correlation coefficient and the overall $P$-value are -0.89 and 0.000 I, respectively.

of cataract was exponential. With the regression line starting with the cataract incident of approximately 55\%, the $R^{2}$ value comes out to near 0.8 , with the Spearman's rank-order correlation coefficient of -0.89 and the $P$-value of $<0.0001$. The inhibitory effect of caffeine against cataract formation is thus statistically highly significant. The cataract-lowering effect becomes highly visible as the caffeine consumption levels reach near $50 \mathrm{mg}$ and then nearly complete at $100 \mathrm{mg} /$ day. Therefore, there is evidence of saturation kinetics coming into play, characteristic of the biological effectiveness of treatment with exogenous agents. In the USA, using one cup of ordinary coffee $(8 \mathrm{Oz}, 237 \mathrm{~mL})$ provides 95-200 mg of caffeine. Thus, it lies close to the amount found positively correlated with lower incidence of cataract blindness.

The lower incident of cataract blindness in countries with higher levels of caffeine use is in line with the experimental findings referred earlier, showing inhibition of cataract formation in animals given caffeine either systemically with the diet or through topical eye drops in galactosemic animals, and also through eye drops in rabbits exposed to UV irradiation. This is also in agreement with other studies, where we have shown that caffeine can inhibit cataractogenesis induced directly by photochemical generation of ROS in vitro.

\section{Discussion}

Cataract development is the major cause of visual impairment and blindness throughout the world. ${ }^{1-3}$ Etiologically, its origin and formation is related to several confounding factors such as aging by itself, genetic factors, increasing incidence of diabetes, nutritional deficiencies, smoking, continued penetration of light into the eye, and consequent induction of oxidative stress through intraocular formation of oxygen free radicals. The latter has been suggested to be one of the primary factors involved in the formation of cataracts, as evident by its higher prevalence in countries that receive excessive solar radiation and consume diets that are low in nutritional antioxidants and scavengers of oxygen free radicals. Accordingly, the attempt of cataract surgery in removing blindness due to cataracts gets significantly minimized. In India, for example, the number of people with cataract blindness is likely to remain the same as it is today or most likely to increase. ${ }^{3}$ Further studies on the prevention of cataracts by methods such as preventing the increase in obesity and diabetes, modulating light exposure penetrating in the eye, and increasing use of antioxidant nutrients are considered highly desirable. Previously described studies with experimental animals as well as with certain human epidemiological studies strongly suggest that the use of certain antioxidant nutrients is highly effective in inhibiting the formation of cataracts. Therefore, the primary aim of this investigation was to assess the significance of these experimental studies with regard to the prevalence of cataract blindness in humans as determined by the consumption of coffee as a source of caffeine. While coffee does contain certain other antioxidants, such as chlorogenic acids, they are destroyed while roasting the raw coffee beans before their use for the preparation of coffee. The present investigations seeking to correlate the amount of coffee consumption with cataract incidence were also prompted by reports showing that its consumption decreases the risk of the development of type 2 diabetes, ${ }^{41,42}$ a disease known to accelerate the formation of age-dependent cataract. In addition, it has been suggested to prevent liver cirrhosis and certain cancers. ${ }^{43-45}$ Thus, the significance of any toxic effects of caffeine as reported in earlier literature has now been greatly minimized. The US Food and Drug Administration has listed caffeine as a fairly safe compound. Clinically, the most compelling evidence of its nontoxicity has been proven by its wide use in treating diseases associated with neural and muscular dysfunctions, such as the common age-associated dementia, and the Alzheimer's and Parkinson's diseases, ${ }^{46-53}$ with significant success. While the biochemistry of these diseases is yet only partially understood, it is widely believed that their pathogenesis is strongly related to oxidative damage ${ }^{55}$ to the neural and muscular tissues in question, especially in the case of Alzheimer's disease.$^{55}$ Thus, there are significant similarities in the biochemistry of these diseases with that of the 
pathogenesis of cataracts, at least in terms of the formation of lipid peroxidation products such as malondialdehyde ${ }^{55}$ and the presence of DNA degradation products such as

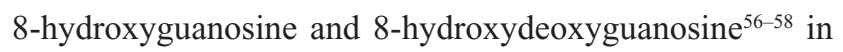
the neural tissues, similar to that in the lens. Their formation in the neural tissues may precede the formation of intracellular Tau-based fibrous tangles and the appearance of extracellular plaques due to $\beta$-amyloid deposition. Apparently, all these processes are initiated by an early generation of ROS by the interaction of trace metals and oxygen. ${ }^{59-61}$ The $\beta$-amyloid can itself lead to the generation of oxygen free radicals. ${ }^{62}$ The concept of oxidative stress is also supported by the effectiveness of ascorbate in treating the disease, ${ }^{59}$ similar to that in the case of cataracts. ${ }^{20-23}$ Treatment with caffeine has also been seen to delay the formation of plaques and the tangles, while also minimizing memory loss.

In addition to its antioxidant effects, caffeine can help overcome the neural transmission defects by acting as an antagonist of adenosine, which is well known to modulate nerve transmission by binding to the G-protein (Gi)-linked receptors. ${ }^{63-67}$ This binding is followed by the ultimate generation of the subunits ( $\mathrm{G} \alpha \mathrm{i}$ and $\beta \gamma)$ that de-energize the cells by inhibiting adenylyl cyclase and cyclic adenosine monophosphate synthesis, and inhibiting neurotransmitter release by inhibiting calcium transport into the presynaptic nerve terminals. Caffeine antagonizes this process by competitively inhibiting the binding of adenosine to the receptor. Adenosine's inhibitory effects on nerve transmissions are thus reversed by caffeine. Adenosine binding to the G-protein receptor (instead of Gi) also inhibits dopamine release. Caffeine abolishes this unwanted effect as well. It is thus highly possible that the helpful effects of caffeine as an antioxidant are synergistically related to its action as an antagonist of adenosine.

Similar to the action of caffeine against oxidative stress in neural tissue and the previously reported effect against cataract formation in animal studies, its effectiveness in the observed lowering in the incidence of cataract in humans consuming greater amounts of caffeine could also be due to its oxy-radical scavenging activity as one of the possible mechanisms. The oxy-radical scavenging activity of caffeine has been more specifically confirmed in the organ culture studies showing it to act by scavenging the hydroxyl radicals detected by electron spin resonance spectroscopy.

Another action of caffeine in humans when present at appropriately high levels, as likely to be the case in the group consuming more than $200 \mathrm{mg}$ of caffeine per day, is to act as inhibitor of phosphodiesterase activity, helping to maintain a higher levels of cyclic adenosine monophosphate. This is expected to activate protein kinases and subsequent stimulation of tissue metabolism including pathways leading to adenosine triphosphate generation. Indeed, we have shown that the levels of adenosine triphosphate are higher in the lenses cultured with caffeine as well as when it was given in vivo. ${ }^{23,24}$ The presence of caffeine has also been shown to accelerate synthetic processes associated with lens cell development, ${ }^{68}$ an effect also found useful in cloning of embryonic stem cells. ${ }^{69}$

We have recently reported that induction of oxidative stress during cataract formation, beside depleting the antioxidant reserves, triggers an onset of a genetic dysregulation process initiated by inducing an upregulation of certain miRNAs and consequent gene silencing caused by deactivation of the mRNAs involved in the translation of various antioxidant enzymes. Several miRNAs known to exert such silencing have been shown to be significantly upregulated with the very beginning of cataract formation in the lenses of galactosemic animals. Interestingly, such upregulation has been found to be thwarted by caffeine, suggesting another pathway of the physiologically beneficial effects of caffeine in lens.

The results thus indicate to the likelihood that the observed protective effect of caffeine against cataract formation in humans and experimental animals is likely to be multifactorial in nature, involving its action as a scavenger of oxygen free radicals, acting in combination with its property of acting as an inhibitor of phosphodiesterase and preventing gene silencing. All of them are physiologically beneficial reactions.

It has been previously reported ${ }^{70-72}$ that intake of a coffee drink by glaucoma patients can increase the intraocular pressure by $1-2 \mathrm{mmHg}$, suggesting the possibility of a toxic effect of caffeine in the long run. However, such increases have not been observed regularly. Additionally, this is not supported by studies with pure caffeine. ${ }^{73,74}$ The small rise in intraocular pressure with coffee drinking, if any, is obviously due to increase in water absorption in glaucoma, ${ }^{75,76}$ a fact used for diagnosis of the disease itself.

This study indicating a possible preventive effect of coffee and caffeine against cataract formation in humans is thus considered useful for further controlled clinical studies evaluating the effect of coffee and caffeine against cataract. In addition, the study also points out the desirability of further mechanistic studies on the molecular mode caffeine's action using in vitro and in vivo experimental animal models. 


\section{Disclosure}

The author reports no conflicts of interest in this work.

\section{References}

1. Thylefors B, Negrel AD, Pararajasegram R, Dadzie KY. Global data on blindness. Bull World Health Organ. 1975;73:15-121.

2. Resnifoff S, Pascolini D, Etya ale D, et al. Global data on visual impairment in the year 2002. Bull World Health Organ. 2004;82:844-851.

3. Murthy GVS, Gupta SK, John N, Vashist P. Current status of cataract blindness in vision 2020. The right to sight initiative in India. Indian J Ophthalmol. 2008;56(6):489-494.

4. Varma SD, Est TK, Richards RD. Protection against superoxide radicals in rat lens. Ophthalmic Res. 1977;9(6):421-431.

5. Varma SD, Kumar S, Richards RD. Light-induced damage to ocular lens cation pump: prevention by vitamin C. Proc Natl Acad Sci US A. 1979;76(7):3504-3506.

6. Varma SD, Chand D, Sharma YR, Kuck JF, Richards RD. Oxidative stress in lens and cataract formation: role of light and oxygen. Curr Eye Res. 1984;3(2):35-57.

7. Varma SD, Kovtun S, Hegde K, Yin J, Ramnath J. Effect of high sugar levels on miRNA expression. Studies with galactosemic mice lens. Mol Vision. 2012;18:1609-1618.

8. Varma SD, Chandrasekaran K. High sugar-induced repression of antioxidant and anti-apoptotic genes in lens: reversal by pyruvate. Mol Cell Biochem. 2015;403(1-2):149-158.

9. Varma SD. Ascorbic acid and the eye with special reference to the lens. Ann N Y Acad Sci. 1987;498(1):280-306.

10. Linklater HA, Dzialoszynski T, McLeod HL, Sanford SE, Trevithick JR. Modeling of cataractogenesis XI. Vitamin C reduces Y-crystallins leakage from lenses in diabetic rats. Exp Eye Res. 1990;51(3):241-247.

11. Trevithick JR, Linklater HA, Milton KP, Dzialoszynski T, Sanford SE. Modeling cortical cataractogenesis. Activity of vitamin E and esters in preventing cataracts and gamma-crystallins leakage form lenses in diabetic rats. Ann N Y Acad Sci. 1989;570(1):358-371.

12. Varma SD, Morris S. Peroxide damage to the eye lens in vitro prevention by pyruvate. Free Radical Res Commun. 1988;4(5):283-290.

13. Varma SD, Ramachandran S, Devamanoharan PS, Morris SM, Ali AH. Prevention of oxidative damage to rat lens in vitro by pyruvate: possible attenuation in vivo. Current Eye Res. 1995;14(8):643-649.

14. Varma SD, Mikuni I, Kinoshita JH. Flavonoid as inhibitors of lens aldose reductase. Science. 1975;188(4194):1215-1216.

15. Varma SD, Mizuno A, Kinoshita JH. Diabetic cataracts and flavonoids. Science. 1977;195(4274):205-206.

16. Muthenna P, Suryanarayana P, Gunda J, Petrash JM, Reddy GB. Inhibition of aldose reductase by dietary antioxidant curcumin: mechanism of inhibition, specificity and significance. FEBS Lett. 2009;583(3): 3637-3642.

17. Suryanarayana P, Saraswat M, Mridula T, Prasanna KT, Krishnaswamy K, Reddy GB. Curcumin and turmeric delay streptozotocin-induced diabetic cataract in rats. Invest Ophthalmol Vis Sci. 2005;46(6): 2092-2099.

18. Hedge KR, Varma SD. Prevention of cataract by pyruvate in experimentally diabetic mice. Mol Cell Biochem. 2005;269(1):115-120.

19. Varma SD, Devamanoharan P, Mansour S, Teter B. Studies on Emory mouse cataracts: oxidative factors. Ophthalmic Res. 1994;26(3): 141-148.

20. Robertson JM, Donor AP, Trevithick JR. A possible role of vitamins C and $\mathrm{E}$ in cataract prevention. Am J Clin Nutr. 1991;53(1):346S-351S.

21. Jacques PF, Chylack LT Jr. Epidemiological evidence of a role for the antioxidant vitamins and carotenoids in cataract prevention. Am J Clin Nutr. 1991;53(1):352S-355S.

22. Valero MP, Fletcher AE, De Stavola BL, Vioque J, Alepuz VC Vitamin $C$ is associated with reduced risk of cataract in a Mediterranean population. J Nutr. 2002;132(6):1299-1306.

23. Taylor A, Jacques PF, Epstein EM. Relations among aging, antioxidant status, and cataract. Am J Clin Nutr. 1995;62(6):139S-1447S.
24. Varma SD, Hegde KR, Kovtun S. UV-B induced damage to lens in vitro. Prevention by caffeine. J Ocul Pharmacol Ther. 2008;24(5): 439-444.

25. Varma SD, Hegde KR. Kynurenine-induced photo oxidative damage to lens in vitro: protective effect of caffeine. Mol Cell Biochem. 2010; 340(1-2):49-54

26. Varma SD, Hegde KR. Prevention of oxidative damage to lens by caffeine (Vivo). J Ocul Pharmacol Ther. 2010;26(1):73-77.

27. Varma SD, Hegde KR, Kovtun S. Oxidative stress in lens in vivo: inhibitory effect of caffeine. A preliminary report. Mol Vis. 2010;16:501-505.

28. Varma SD, Kovtun S, Hegde K. Effectiveness of topical caffeine in cataract prevention: studies with galactose cataract. Mol Vis. 2010;16: 2626-2633.

29. Varma SD, Hegde K, Kuvtun S. Inhibition of selenite induced cataract by caffeine. Acta Opthalmol. 2010;88(7):e254-e259.

30. Kronschläger M, Lofgren S, Yu Z, Talebizadeh N, Varma SD, Söderberg PG. Caffeine eye drops protect against UV-B cataract. Exp Eye Res. 2013;113:26-31.

31. Shi X, Dalal NS, Jain AC. Antioxidant behavior of caffeine: efficient scavenging of hydroxyl radicals. Food Chem Toxicol. 1991; 29(1):1-6.

32. Stadler RH, Fay LB. Antioxidant reactions of caffeine: formation of 8-oxocaffeine (1,3,7-trimethyl uric acid) in coffee subjected to oxidative stress. J Agric Food Chem. 1995;43(5):1332-1338.

33. Devasagayam TPA, Kamat JP, Mohan H, Kesavan PC. Caffeine as an antioxidant: inhibition of lipid peroxidation induced by reactive oxygen species. Biochim Biophys Acta. 1996;1282(1):63-70.

34. Varma SD, Kovtun S. Protective effect of caffeine against high sugar induced transcription of microRNAs and consequent gene silencing: a study with galactosemic mice. Mol Vision. 2013;19:493-500.

35. Table ERC.5 Resource Consumption. World Resources 2000-2001. Available from: http://www.griequity.com/resources/BusinessGuides/ DemographicsData/energy/energyresourceconsn.pdf. Accessed July 7 , 2015.

36. Current world annual coffee consumption per capita. ChartsBin [updated 2011]. Available from: http://chartsbin.com/view/581. Accessed January 21, 2016.

37. List of countries by tea consumption per capita. Wikipedia [updated November 22, 2015]. Available from: https://en.wikipedia.org/ wiki/List_of_countries_by_tea_consumption_per_capita. Accessed January 21, 2015.

38. List of countries by coffee consumption per capita. WOW [updated January 31, 2015]. Available from: http://us.wow.com/wiki/List_of_ countries_by_coffee_consumption_per_capita. Accessed January 21, 2015.

39. Farrah A. Coffee. In: Yi-Fang Chu, editor. Emerging Health Effects and Disease Prevention. Hoboken, NJ: John Wiley \& Sons, Inc.; 2012: 21-58.

40. Farrah A, de Paulis T, Trugo LC, Martin PR. Effect of roasting on the formation of chlorogenic acid lactones in coffee. J Agric Food Chem. 2005;53(5):1505-1513.

41. Salazar-Martinez E, Willett WC, Ascherio A, et al. Coffee consumption and risk for type 2 diabetes mellitus. Ann Intern Med. 2004; 140(1):1-8.

42. Huxley R, Lee CM, Barzi F, et al. Coffee, decaffeinated coffee, and tea consumption in relation to incident type 2 diabetes mellitus: a systematic review with meta-analysis. Arch Intern Med. 2009; 169(22):2053-2063.

43. Klatsky AL, Morton C, Udaltsova N, Friedman GD. Coffee, cirrhosis, and transaminase enzymes. Arch Intern Med. 2006;166(11): 1190-1195.

44. Cadden IS, Partovi N, Yoshida EM. Review article: possible beneficial effects of coffee on liver disease and function. Aliment Pharmacol Ther. 2007;26(1):1-8.

45. Inoue M, Yoshimi I, Sobue T, Tsugane S; JPHC Study Group. Influence of coffee drinking on subsequent risk of hepatocellular carcinoma: a prospective study in Japan. J Natl Cancer Inst. 2005;97(4):293-300. 
46. Maia L, de Mendonça A. Does caffeine intake protect from Alzheimer's disease? Eur J Neurol. 2002;9(4):377-382.

47. Johnson-Kozlow M, Kritz-Silverstein D, Barrett-Connor E, Morton D. Coffee consumption and cognitive function among older adults. Am J Epidemiol. 2002;156(9):842-850.

48. Lopez-Garcia E, van Dam RM, Willett WC, et al. Coffee consumption and coronary heart disease in men and women: a prospective cohort study. Circulation. 2006;113:2045-2053.

49. Arendash GW, Cao C. Caffeine and coffee as therapeutic against Alzheimer's disease. J Alzheimer's Dis. 2010;20(Suppl 1):S117-S126.

50. Lindsay J, Laurin D, Verreault R, et al. Risk factors for Alzheimer's disease: a prospective analysis from the Canadian Study of Health and Aging. Am J Epidemiol. 2002;156(5):445-453.

51. Ritchie K, Carriere I, de Mendonca A, et al. The neuroprotective effects of caffeine: a prospective population study. Neurology. 2007; 69(6):536-545.

52. Ross GW, Abbott RD, Petrovich H, et al. Association of coffee and caffeine intake with the risk of Parkinson disease. JAMA. 2000;283: 2674-2679.

53. Xuesong Chen, Othan G, Jonathan DG. Caffeine protects against disruptions of the blood-brain barrier. J Alzheimer's Dis. 2010; 20(Suppl 1):S127-S141.

54. Nunomura A, Perry G, Aliev G, et al. Oxidative damage is the earliest event in Alzheimer disease. J Neuropathol Exp Neurol. 2001;60(8): 759-767.

55. Pratico D, Sung S. Lipid peroxidation and oxidative imbalance: early functional event in Alzheimer's disease. J Alzheimer's Dis. 2004; $6(2): 171-175$.

56. Mecocci P, MacGarvey U, Bea MG. Oxidative damage to mitochondrial DNA is increased in Alzheimer's disease. Ann Neurol. 1994;36(5): 747-751.

57. Wang J, Marksbery WR, Lovell MA. Increased oxidative damage in nuclear and mitochondrial DNA in mild cognitive impairment. J Neurochem. 2006;96(3):825-832.

58. Zhou C, Huang Y, Przedborski A. Oxidative stress in Parkinson's disease: a mechanism of pathogenic and therapeutic significance. Ann NY Acad Sci. 2008;1197:93-104.

59. Heo JH, Leo H, Lee KM. The possible role of antioxidant vitamin C in Alzheimer's disease treatment \& prevention. Am J Alzheimer's Dis Other Demen. 2013;28(2):120-125.

60. Smith MA, Harris PL, Sayre LM, Perry G. Iron accumulation in Alzheimer disease is a source of redox generated free radicals. Proc Natl Acad Sci U S A. 1997;94(18):9866-9868.

61. Gesell W, Conrad R, Hickethier M, et al. Decreased catalase activity but unchanged superoxide dismutase activity in brains of patients with dementia of Alzheimer type. J Neurochem. 1995;64(3):1216-1223.
62. Reddy PH. Amyloid precursor protein-mediated free radicals and oxidative damage: implications for the development and progression of Alzheimer's disease. J Neurochem. 2006;96(1):1-13.

63. Smith MA, Hirari K, Hsiao K, et al. Amyloid-beta deposition in Alzheimer 'transgenic mice are associated with oxidative stress. J Neurochem. 1998;70(5):2212-2215.

64. Wilson DF. Effect of caffeine on neuromuscular transmission in rats. Am J Physiol. 1973;225(4):862-865.

65. Daly JW, Burns RF, Snyder SH. Adenosine receptor in the central nervous system: relationship to the central actions of methylxanthines. Life Sci. 1981;28(19):2083-2097.

66. Morgan MD, Vestal RE. Methylxanthine effects on caudate dopamine release as measured by in vivo electrochemistry. Life Sci. 1989;45(21): 2025-2039.

67. Pedata F, Giovanelli L, De Samo P, Pepeu B. Effect of adenosine derivatives and caffeine on acetylcholine release from the brain synaptosomes: interaction with muscarinic autoregulatory mechanisms. J Neurochem. 1986;46(5):1593-1598.

68. Creighton MO, Trevithick JR. Effect of cyclic AMP, caffeine and theophylline on differentiation of lens epithelial cells. Nature. 1974; 249:767-768.

69. Tachibana M, Amato P, Sparman M, et al. Human embryonic stem cells derived by somatic cell nuclear transfer. Cell. 2013;153(6): 1228-1238.

70. Higginbotham EJ, Kilimanjaro HA, Wilensky JT, Batenhorst RL, Hermann D. The effect of caffeine on intraocular pressure in glaucoma patients. Ophthalmology. 1989;96(5):624-626.

71. Avisar R, Avisar E, Weinberger D. Effect of coffee consumption on intraocular pressure. Ann Pharmacother. 2002;36(6):992-995.

72. Chandrasekaran S, Rochtchina E, Mitchell P. Effect of caffeine on intraocular pressure: The Blue Mountains Eye Study. J Glaucoma. 2005; 14(6):504-507.

73. Adams BA, Brubaker RF. Caffeine has no clinically significant effect on aqueous humor flow in the normal human eye. Ophthalmology. 1990; 97(8):1030-1031.

74. Chandra P, Gaur A, Varma S. Effect of caffeine on the intraocular pressure in patients with primary open angle glaucoma. Clin Ophthalmol. 2011;5:1623-1629.

75. Leydhecker W. The water-drinking test. Br J Ophthalmol. 1950;34(8): 457-479.

76. Agarwal LP, Sharma CK. Two provocative tests for glaucoma. Br J Ophthalmol. 1955;37:330-335.
Clinical Ophthalmology

\section{Publish your work in this journal}

Clinical Ophthalmology is an international, peer-reviewed journal covering all subspecialties within ophthalmology. Key topics include: Optometry; Visual science; Pharmacology and drug therapy in eye diseases; Basic Sciences; Primary and Secondary eye care; Patient Safety and Quality of Care Improvements. This journal is indexed on Submit your manuscript here: http://www.dovepress.com/clinical-ophthalmology-journal
Dovepress

PubMed Central and CAS, and is the official journal of The Society of Clinical Ophthalmology (SCO). The manuscript management system is completely online and includes a very quick and fair peer-review system, which is all easy to use. Visit http://www.dovepress.com/ testimonials.php to read real quotes from published authors. 